\title{
The Empirical Analysis of Financial Agglomeration in Guangdong, Hong Kong and Macao
}

\author{
Jiantao Jiang \\ Guangdong Baiyun University, Guangzhou, Guangdong, 510450
}

Keywords: Financial Agglomeration, Guangdong, Hongkong and Macao, Empirical Analysis

\begin{abstract}
With the rapid development of the global financial industry and the rise of regional financial centers in emerging market countries, the problem of financial agglomeration has become one of the focuses of economics, sociology and geography. In recent years, the research on industrial agglomeration in manufacturing industry is relatively mature, and the research on financial agglomeration is still relatively lacking. Industrial agglomeration theory can provide theoretical support for the construction of financial agglomeration and financial center. The Greater Pearl River Delta Region is one of the most developed economic circles in China. Under the background of stable economic growth, how to promote the financial agglomeration in the Greater PRD and enhance the competitiveness of the financial industry is a major issue in the financial development.
\end{abstract}

\section{Introduction}

Traditional economics concerns about space issues. From the classical position to the new economic geography, the so-called regional sciences or regional economics aim to introduce the "space" elements into the mainstream economic analysis system. One of the obvious features of economic activity from a spatial point of view is "gathering." Both economists and geographers have noticed that the positioning of industrial activities and the form of external economies of scale in the organization are the emergence of agglomeration or localized economy. Industrial agglomeration is an important driving force for promoting industrial development and enhancing regional competitiveness. Location remains the main basis for determining the spatial distribution of economic elements [1].

\section{Financial Accumulation Mechanism of the Internal Theory}

Any theory of regional and urban development depends on the role of increasing returns to scale and the externalities of Liang Qi. The increasing returns of agglomeration include economies of scale and economies of scope. Internal economies of scale are mainly internal to the enterprise. The financial industry also has significant economies of scale. The main reasons for this include the economy of professional division and collaboration of financial institutions, the saving of financial marketing costs, the economies of scale of technological development, the effects of scale management, the saving of financing costs and the improvement of risk-resisting capabilities. The realization of economies of scale by a single financial institution in terms of products, branches and enterprises as a whole made it possible for financial institutions to produce rich products, increase in numbers and expand their scale to a certain extent. The external economies of scale and the formation of agglomeration are closely related. The financial sector can provide financing and investment facilitation by saving the balance of working capital, improving market liquidity, reducing financing costs and investment risks, and promoting the development of other industries. In turn, the development of other industries has led to a further increase in demand for finance, thereby promoting the expansion and deepening of financial agglomeration [2].

Whether it is economies of scale or economies of scope, wherever they exist, they enable firms to generate incentives for agglomeration by increasing the number of products they produce or the variety of products they produce. As technology becomes more and more important, the external 
economy is also becoming more and more important, and exogenous returns are becoming more common. Whether endogenous or exogenous, as long as there is an increasing return, it will stimulate the concentration of enterprises [3].

The financial industry does not seem to have a "real" product, but by no means does it mean that it does not incur the cost of delivering the product. Here we use the concept of "transaction costs" to approximate alternative transportation costs. Williamson defines the market organization analysis of transaction costs and puts forward the decision of explaining the regulation structure of economic activities in three dimensions of transaction uncertainty, transaction frequency and asset specificity. In general, the market is an effective trading coordination tool when all three dimensions are at a low level. In the case of high transaction uncertainty, high transaction frequency and high asset specificity, the enterprise registration regulator replaces the market equality the regulatory structure is an efficient organizational arrangement. When the three dimensions of the transaction are in between these two states, bilateral, multilateral and mixed intermediary organizations are the most effective organizational structures. Agglomeration is one of them [4].

As an industry that produces specialized information, the transaction cost of finance is mainly the cost of information processing, including the cost of information acquisition, information specialty, information dissemination and information accumulation. Although the emergence of financial agglomeration areas reduces the cost of information processing in the agglomeration area, the cost of information processing outside the agglomeration area increases with distance. And much of the information needs to be delivered face to face. Therefore, the distance is still an important factor affecting the transaction costs, transaction costs increased with the distance is one of the constraints of concentration. Market behavior without transaction costs is not possible. Another important factor constraining agglomeration is external diseconomies. When one side's production or consumption behavior affects the production or consumption activities of other parties that are not involved, it will lead to the external economy or the external economy. Economies of scale means that the average cost of individual firms or the increase of returns will result from the increase of the scale and output of the whole industry. Conversely, it is not economical for the outside world. Financial accumulation is often a big city with a high concentration of population, and the carrying capacity of land itself is limited. The excessive concentration of population and capital leads to the increase of land cost, traffic congestion, increase of labor costs, deterioration of the ecological environment, etc., which will raise the production cost. The external diseconomies of agglomeration have limited the possibility of regional agglomeration to an appropriate level [5].

\section{Major Financial Problems in the Greater Pearl River Delta Region}

Although the existence of financial services does not depend on natural resources and service providers have no restrictions on the choice of location, financial centers tend to focus on certain areas. An economy that is to become an international financial center must have the capacity to attract a variety of financial institutions and international financial activities. The proportion of economic system in international financial activities, or the concentration of financial market activities, is an important indicator of the status of international financial center. The concentration of international financial activities in stocks, bonds, bank loans, foreign exchange and derivatives can provide a more comprehensive assessment of the global share of financial activities in the economy. The importance of an international financial center for an economy increases with its share of global financial market activity.

Financial centers must first be economic centers, that is, they should have strong economic strength, strong economic agglomeration and proliferation capacity, have a high degree of regional economic integration, have close economic ties with their neighboring hinterlands and thus have a direct impact on the hinterland economy the scale and speed of development. Without a vast financial hinterland and without integrated regional economic support, the development of a financial center may be limited. Because a financial center needs a vast financial hinterland to provide a channel for the flow of financial resources, it is sufficient to provide ample financial 
hinterland for some financial centers that support industrial development as their main function instead of merely focusing on financial transactions It is all the more important for diversified sources of financing and funding.

The empirical analysis of this paper shows that the economies of scale of financial conglomeration in Guangzhou and Shenzhen have not yet been formed and have not reached the stage of increasing returns. As a result, economies of scale in the financial industry have limited the driving force for financial agglomeration. Compared with the major financial centers in China, Guangzhou and Shenzhen are under-represented. There is still a certain gap between Guangzhou, Shenzhen and Zhaoting and Shanghai in terms of the output value of the financial and insurance industries, the output value of the tertiary industry, deposits and loans of financial institutions and financial-related ratios.

Guangzhou and Shenzhen As the financial centers that are open and close, inadequate financial resources and inadequate financial development have undoubtedly adversely affected the construction of a hierarchical system of financial centers in the Greater PRD. On the one hand, the construction of Hong Kong's international financial center lacks strong support and cooperation. On the other hand, there is not enough radiation and support for other neighboring cities.

The Pearl River Delta is the financial center of Guangzhou, Shenzhen, the core of the financial hinterland. For a financial center whose main function is to support industrial development rather than merely focus on financial transactions, it is particularly important to have a well-developed financial hinterland to provide them with diversified financing needs and funding channels. However, compared with the three major economic circles in our country, the economic development in the Pearl River Delta region is limited. According to the report on China's regional financial operation, the development of the tertiary industry in the three major economic circles in China lags behind in general, and the tertiary industry in the Pearl River Delta has relatively slow growth. The Pearl River Delta Region's GDP accounts for the entire country, and there is a big gap between the PRD region and the Yangtze River Delta in respect of fixed asset investment, local fiscal revenue, and actual utilization of foreign investment. Import and export trade performance is acceptable. Economic development in the Pearl River Delta is at a critical period of transformation. From the traditional mode of extensive growth and expansion to intensive transformation, from the traditional light industry to heavy industry, from labor-intensive industries to capital- and technology-intensive industries, the development of services Industry and independent innovation ability. Only by soundly and rapidly developing the economy can we provide a strong foundation for the establishment of financial centers in Guangzhou and Shenzhen.

\section{Build Hong Kong-centered Greater Pearl River Delta Financial Gathering Area}

The construction of a financial center in a country or region should be multi-level, not only for building an international financial center but also for building domestic and regional financial centers. The Greater Pearl River Delta should give full scope to its comparative advantages and build a multi-level financial center according to the actual conditions in the region. Different levels of international financial centers have different stages of development and should have different targets of service and functions. First of all, we must clarify the positioning of the financial functions of each central city, make each city differentiate and compete with each other and complement each other's functions, and promote a multi-level financial center system to exert its agglomeration effect and radiation function. The Greater Pearl River Delta's financial agglomeration can not develop in isolation. It must take a long-term and scientific planning in the context of the economic and financial cooperation between Guangdong, Hong Kong and Macao. Grasping the major historical opportunities for Guangdong's establishment of a financial reform integrated pilot zone, in order to adapt to the trend of financial globalization, we should establish Hong Kong as the center, Guangzhou and Shenzhen as the financial support, and other cities in the Pearl River Delta as the financial pivot to radiate Asia-Pacific with global competition Powerful financial gathering area.

Hong Kong and Macao have a large number of RMB circulation, monetary cooperation is 
imperative. We may consider widening the RMB backflow channel and setting up the three banks' interbank borrowing market for various business cooperation such as settlement of transactions in RMB, Hong Kong dollar and Australian dollar, exchange of notes, agency broking, project financing and syndicated loans. Allowing the Hong Kong dollar to settle and liquidate in Guangdong Province and expediting the settlement and liquidation of the renminbi in Hong Kong and Macau allows swaps between Renminbi, Hong Kong dollar and Australian dollar in Hong Kong, Guangdong and Macao financial institutions. While doing a good job of piloting RMB settlement of trade in goods between Guangdong and Hong Kong and Macao, pilot pilots for personal and foreign currency exchange franchises will be conducted in the pilot area. Regulate the liquidity of the renminbi.

To further promote the development of financial agglomeration and the construction of a financial center in the Greater PRD Region must be organically integrated with deepening the reform of the financial system in Guangdong and improving the financial environment. Establish an open financial service system compatible with Guangdong's economic liberalization. Mainly from the following aspects of promoting reform first, draw lessons from the successful experience of Hong Kong and Macao financial system, for the first to implement and Hong Kong, Macao and international standards. Second, speed up the property rights system and the construction of modern enterprise system to cultivate the micro trading subjects in financial markets. Thirdly, the Bank will clarify the efficiency target of financial supervision, continue to improve its financial supervision system, and implement audits of financial institutions, including compliance supervision, market access, market positioning and market supervision. Fourth, reform the interest rate management mechanism, gradually perfect the financial market system and encourage market competition. Fifth, improve the financial ecological environment, improve the financial development and construction, optimize the government environment, and provide the financial institutions with a fair, fair and convenient business environment.

\section{Conclusions}

China is a huge economy with very different developments in different regions and the interaction between regions is quite complicated. Due to limited space, this article focuses on the study of financial agglomeration in the Greater PRD. It does not conduct any expansionary analysis of the surrounding areas and lacks detailed comparative analysis of other major financial centers in the country. However, it is necessary to conduct a comprehensive and multi-angle study on China's financial agglomeration and it is also the direction of future research.

\section{Acknowledgements}

Guangdong, Department of Education, quality project finance specialty construction.

\section{References}

[1] Chen Aiyan, Ning Junming. Pearl River Delta financial agglomeration and economic growth [J]. Hainan Finance. 2008 (08):15-18.

[2] Liu Hong. Financial agglomeration of the regional economy growth and radiation effects of [J]. Shanghai Finance. 2008 (06):77-78.

[3] Chen Wenfeng, Ping Ying. The Relationship between Financial Industry Agglomeration and Economic Growth in Shanghai [J]. Statistics and Decision. 2008 (10):102-105.

[4] Huang Jieyu. Review of financial agglomeration [J]. Industrial Technology Economics. 2008 (01):89-99.

[5] Teng Chunqiang. Study on the development motivation of financial enterprise cluster under the evolutionary perspective [J] .Shaanxi Economic Management. 2007 (02):18-21. 